UVX 2008 (2009) 127-132

(C) EDP Sciences, 2009

DOI: $10.1051 / \mathrm{uvx} / 2009020$

\title{
Optical and photonic material hardness for energetic environments
}

\author{
G. Origlio ${ }^{1,2}$, S. Girard ${ }^{3}$, R. Boscaino ${ }^{2}$, A. Boukenter ${ }^{1}$, \\ M. Cannas ${ }^{2}$ and Y. Ouerdane ${ }^{1}$ \\ ${ }^{1}$ Laboratoire H. Curien, UMR CNRS 5516, Université Jean Monnet, 18 rue du Pr. Benoît \\ Lauras 42000, Saint-Etienne, France \\ 2 Dipartimento di Scienze Fisiche ed Astronomiche, 90123 Palermo, Italy \\ ${ }^{3}$ CEA, DAM, DIF, 91297 Arpajon, France
}

\begin{abstract}
We studied the effects of dielectric change in the chemical composition and in the realization procedures under radiation exposure. We have compared the radiation effects on Ge-doped and F-doped fibers and preforms: the first play a crucial role in the photosensitivity property, the second improves the dielectric radiation hardness even at low concentrations. The use of different spectroscopic techniques (RIA, OA, EPR) allow the identification of the point defect formation mechanisms at the origin of the optical degradation properties.
\end{abstract}

\section{INTRODUCTION}

The appearance of new radiative environments integrating silica components, first of all optical fibers [1-3], requires their immunization under ionizing radiation, like $\gamma$ and X-rays or UV laser. Exposure to radiation can induce stable alterations of the material [2], often related to point defects generation and conversion processes [4]. The presence of defects in optical fibers often causes the appearance of new energy levels located inside the band gap of the dielectric [2,5]. As a consequence, the glass absorbs a more important part of the transmitted signal giving rise to an attenuation of the light guided inside and consequently in a degradation of the fibers themselves. The fiber radiation response depends on many intrinsic parameters: core and cladding dopants, impurity content, strain [6,7], which are generally not accessible for researchers. Usually classical optical fibers for telecommunications are used in the IR, from 835 to $1600 \mathrm{~nm}$, where the optical transmission is better. Moreover new technological fields, like medical application and plasma diagnostic, need the use of light guides in the visible and UV region were optical transmission is affected by many losses [2,8-10]. All this well explains the necessity to investigate the exact nature of point defects, checking their origin and properties and so reducing degradation effects also in the UV-visible domain.

In this field we investigated the irradiation influence on both F-doped and Ge-doped silica based optical fiber samples and their original corresponding preforms. The aim is to compare their response after radiation exposure with the purpose of achieving radiation toughness by the knowledge of defect generation mechanisms. The studied samples are prototype not commercialized yet: their future use can be planned for specific fields, like space or nuclear power plants, where expositions to high irradiation doses are expected.

\section{MATERIALS AND METHODS}

Multistep-index "canonical" fibers and preforms are produced by iXFiber S.A.S thought Modified Chemical Vapor Deposition (MCVD) process. Fiber and preforms are made up of four cylindrical layers (core part, zones 1-4) of high pure synthetic silica differently doped, following a multiple step distribution, as shown in the microscopic visions in fig. 1. Fluorine doping profile grows from the 

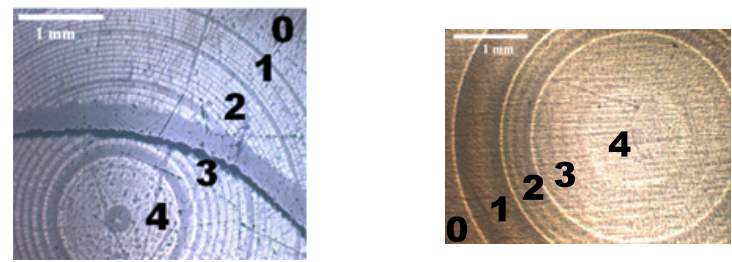

Figure 1. Microscopic views of Ge-doped (left) and F-doped (right) preforms. Numbers from 1 to 4 refer to the zones listed in Table 1 with different amounts of dopants.

Table 1. Parameters related to F-doped and Ge-doped fiber and preform samples.

\begin{tabular}{c|c|ccc|ccc|c}
\hline & Zone & $\begin{array}{c}\mathrm{F} \\
(\mathrm{wt} \%)\end{array}$ & $\begin{array}{c}\text { Ref. } \\
\text { Index } \\
\text { Change } \\
\left(\times 10^{-3} /\right.\end{array}$ & $\begin{array}{c}\text { Preform } \\
\text { diam. } \\
(\mathrm{mm})\end{array}$ & $\begin{array}{c}\mathrm{Ge} \\
(\mathrm{wt} \%)\end{array}$ & $\begin{array}{c}\text { Ref. } \\
\text { Index } \\
\text { Change } \\
\left(\times 10^{-3} /\right.\end{array}$ & $\begin{array}{c}\text { Preform } \\
\text { diam. } \\
(\mathrm{mm})\end{array}$ & $\begin{array}{c}\text { Fiber } \\
\text { diam. } \\
(\mu m)\end{array}$ \\
\hline Cladding & 0 & 0 & 0.33 & 7.47 & 0 & 0.33 & 10.16 & 125 \\
\hline & 1 & 1.8 & -5.9 & 4.44 & 2.5 & 2.19 & 5.02 & 62.5 \\
& 2 & 1.3 & -4.1 & 3.98 & 4.5 & 4.33 & 4.24 & 52.8 \\
& 3 & 0.7 & -2.1 & 3.10 & 8 & 7.97 & 3.10 & 38.6 \\
& 4 & 0.2 & -0.5 & 1.50 & 11 & 11.95 & 1.48 & 18.4 \\
\hline
\end{tabular}

center to the boundaries, whereas germanium has an opposite trend. In each case the layers were deposited in a tube of undoped fused silica which forms the cladding (zone 0). The preform samples have a diameter of about $10 \mathrm{~mm}$, with a $5 \mathrm{~mm}$ inner doped region, and they were cut and polished into plates of approximately $1.5 \mathrm{~mm}$ thickness; the fiber core diameter is $62.5 \mu \mathrm{m}$. The preform and fiber characteristics are summarized in Table 1.

X-ray $(10 \mathrm{keV})$ irradiation at room temperature was conducted by the ARACOR facility at the French atomic energy center (CEA); the dose was varied from $2 \mathrm{kGy}$ to $2 \mathrm{MGy}$, with a dose rate of $0.1 \mathrm{kGy} / \mathrm{s}$. UV exposures at $5 \mathrm{eV}(248 \mathrm{~nm})$ were carried out at room temperature with a $\mathrm{KrF}$ pulsed laser (repetition rate: $10 \mathrm{~Hz}$, duration time: $30 \mathrm{~ns}$; pulse energy: $100-400 \mathrm{~mJ}$ ). Irradiations on fibers were conducted by moving the samples at a constant speed, transversally to the UV laser.

The excess of losses induced by $10 \mathrm{keV}$ X-rays in optical fibers is evaluated at room temperature by in situ Radiation Induced Attenuation (RIA) using a deuterium halogen source (Ocean Optics DH2000) and a spectrometer (Ocean Optics HR4000) located inside the ARACOR chamber. Paramagnetic centers in fibers and preforms were detected at room temperature by Electron Paramagnetic Resonance (EPR) performed on a Bruker EMX spectrometer working at $9.7 \mathrm{GHz}$ (X band) with microwave power of $3.2 \mathrm{~mW}$ and a $100 \mathrm{kHz}$ modulation field. Defect concentration was calculated by comparing the doubleintegrated EPR spectra with a reference signal of $\mathrm{E}^{\prime}$ centers, whose density was determined with an accuracy of $\pm 20 \%$ by spin-echo measurements [11]. In addition, Optical Absorption (OA) spectra on preform samples were carried out by the AVANTES S2000 spectrophotometer with a $\mathrm{D}_{2}$ lamp source; the transmitted light was detected by a 2048 channels charge coupled device (CCD) over an integration time of $5 \mathrm{~ms}$. As the beam spot size diameter is $\leq 0.5 \mathrm{~mm}$, we selectively investigated the different sample zones.

\section{RESULTS AND DISCUSSION}

\subsection{Ge-doped fibers and preforms}

Figure 2(A) shows the $10 \mathrm{keV}$-X-ray RIA spectra measured at room-temperature during the steady-state irradiation at different dose levels (dose rate: $0.1 \mathrm{kGy} / \mathrm{s}$ ) for the Ge-doped fiber sample. For energies 


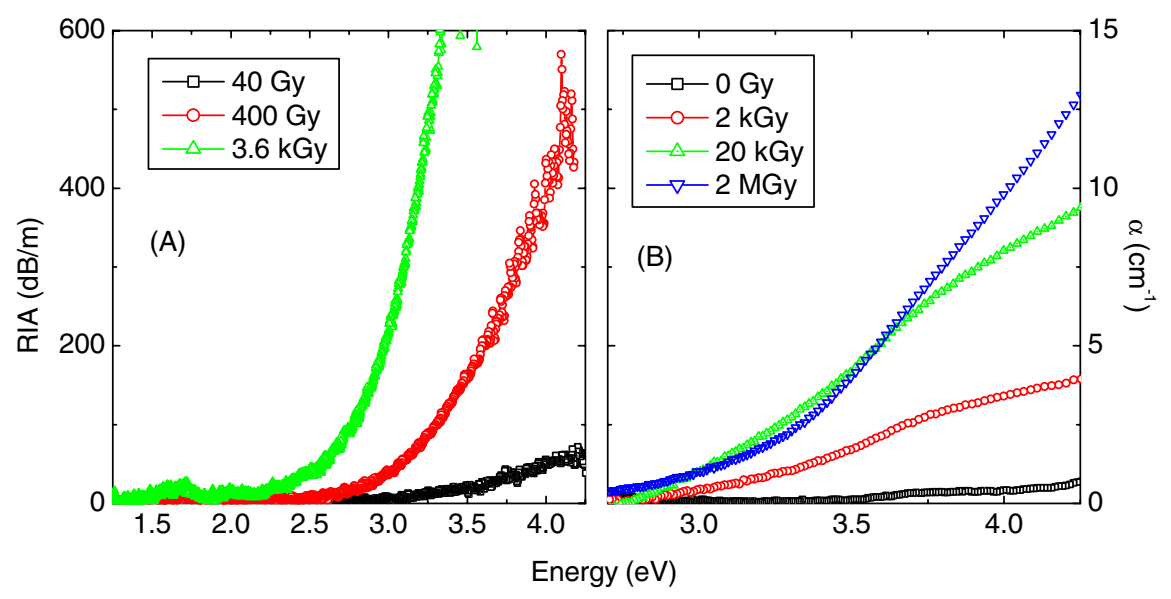

Figure 2. A: Spectral dependence of radiation-induced attenuation (RIA) during $10 \mathrm{keV} \mathrm{X-ray} \mathrm{irradiation} \mathrm{detected}$ in Ge-doped fibers (dose rate of $0.1 \mathrm{kGy} / \mathrm{s}$ ). B: Permanent radiation-induced absorption detected in the central part of preform samples (zone $4,\left[\mathrm{GeO}_{2}\right] \simeq 11 \mathrm{wt} \%$ ) as a function of the $\mathrm{X}$ dose.

greater than $2.5 \mathrm{eV}(\lambda \leq 500 \mathrm{~nm})$, that is in the $\mathrm{UV}$ and visible range, our measurements provide evidence for a strong absorption. Defects absorbing at $\mathrm{E} \geq 4 \mathrm{eV}$ are generated by X-ray irradiation. We need the use of additional spectroscopic techniques to identify the origins of the RIA. To this aim, we achieved OA measurements on preform samples in the UV region (from about $2.5 \mathrm{eV}$ to $5 \mathrm{eV}$ ). Figure 2(B) shows the OA increasing in preforms as a function of the X-dose. With respect to pristine sample (squares), the radiation exposure causes an increasing in transmission losses, in particular OA at about $4 \mathrm{eV}$ grows with the X-dose.

While RIA measurement is a global study on the whole sample, OA investigation on preforms allows to distinguish the several core zones, containing different Ge amounts. In Fig. 2(B) we report the change in the absorption spectrum detected in the central sample region (zone 4), containing $\simeq 11 \mathrm{wt} \%$ of $\mathrm{GeO}_{2}$. We observe that the OA detected in the other core regions decreases with the Ge content, just to become zero in the undoped cladding part (zone 0 ): it is possible to conclude that defects absorbing at $4 \mathrm{eV}$ are concentrated in the central part of the samples with higher Ge-content.

To recognize the defect species responsible of the losses at $4 \mathrm{eV}$, we compare OA results with EPR spectra, detect both in fiber and in preforms. In Fig. 3(A) is reported the EPR signals detected after $20 \mathrm{kGy} \mathrm{X}$-rays exposure: in fiber and preform the same defect species are induced, but with a different efficiency. As the X-dose grows, also paramagnetic defect concentration grows. It is evident that these spectra are composite signals, resulting from the overlap of different contributions. We have found that the signals can be least-square-fitted after irradiation at all doses, by a linear combination of the lineshapes associated with the following Ge-related paramagnetic point defects: $\mathrm{Ge}(1)$, an electron trapped in a fourfold coordinated $\mathrm{Ge}$ atom, $\left(\mathrm{GeO}_{4}\right)^{-}$[12]; $\mathrm{Ge}\left(\mathrm{E}^{\prime}\right)$, an unpaired electron on a threefold coordinated $\mathrm{Ge}\left(\mathrm{Ge}^{\bullet}\right)$ [10]; and $\mathrm{Ge}(2)$, whose structure is still debated between models consisting either in a trapped electron center [13,14] or in a hole center [15,16]. Paramagnetic defect concentration grows with the $\mathrm{X}$ dose both in fibers and in preforms. As Fig. 3(A) qualitatively shows, there are some differences in paramagnetic defect concentrations detected in fibers and in preforms: the drawing process improves defect formation after radiation exposure, but this effect is not constant. We evaluate the $\mathrm{Ge}(1)$ concentration ratio on fiber and preforms at various $\mathrm{X}$ doses finding that for high doses ( $>20 \mathrm{kGy})$ this ratio is about 1 , but it becomes 10 for low irradiations $(\sim 2 \mathrm{kGy})$.

We can plot the absorption coefficient at $4 \mathrm{eV}$, evaluated by the OA measurement, with respect the paramagnetic defect concentration, finding that only Ge(1) EPR signal is linearly proportional to the 

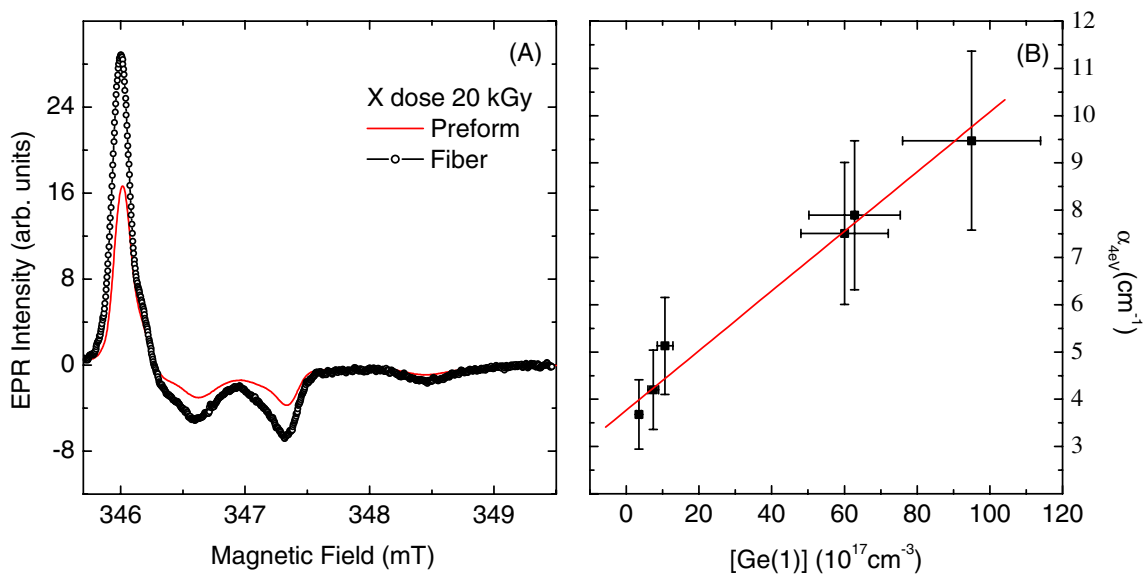

Figure 3. A: EPR signals detected in Ge-doped fiber (line) and preform (circles) after $20 \mathrm{kGy}$ X-rays exposure. B: linear correlation between the $\mathrm{Ge}(1)$ concentration evaluated by EPR measurements and the absorption coefficient at $4 \mathrm{eV}$ estimated by the OA spectra of Fig. 2(B).

OA absorption at $4 \mathrm{eV}$ (Fig. 3(B)). The simultaneous use of different spectroscopic techniques allows to conclude that $\mathrm{Ge}(1)$ centers are responsible for the observed transmission losses and that they are mainly localized in the central part of the samples where the larger germanium content favors the electron trapping on $\mathrm{GeO}_{4}$ sites.

\subsection{F-DOPED FIBERS AND PREFORMS}

Fluorine is usually introduced in the cladding fiber zone with the purpose of lowering the refractive index [17]. Recently it was enlighten the resistance properties of F-doped materials under radiation exposure of different nature [18-21]. From this findings we thought to produce a new fiber generation, as described in Section 2, in which F is introduced not only in the cladding, but also in the core part.

The studied F-doped fibers and preforms were irradiated by UV pulsed laser and X-rays. The radiation induced attenuation detected in fiber samples as a function of the $\mathrm{X}$ dose is shown in Fig. 4(A). Comparing the RIA spectra of Fig. 2(A), it is evident a lower attenuation in F-doped fiber under $\mathrm{X}$ irradiations, also for higher irradiation doses. This is a first confirmation of the improvement in F-doped fiber transmission to respect to Ge-doped ones.

Also after UV exposure F-doped fibers show a good resistance. UV irradiations were conducted at different amounts of energy fluence, from $10 \mathrm{~J} / \mathrm{cm}^{2}$ to $132 \mathrm{~J} / \mathrm{cm}^{2}$ and the inset of Fig. 4(B) shows the EPR spectrum of preform sample after exposure of $8 \times 10^{3} \mathrm{~J} / \mathrm{cm}^{2}$. Many authors showed that in the UV-visible range the response of pure silica core fibers under ionizing radiation is compromised by the presence of the pair Non Bridging Oxygen Hole Center (NBOHC) ( $\left.\equiv \mathrm{Si}-\mathrm{O}^{\bullet}\right)$ and $\mathrm{E}^{\prime}$ center $\left(\equiv \mathrm{Si}^{\bullet \bullet}\right)[8,22]$, originating from the rupture of the so called "strained bonds" ( $\equiv \mathrm{Si}-\mathrm{O}$ ) $[18,20]$. Furthermore in our preform samples after irradiation exposure only $\mathrm{E}^{\prime}$ centers are detected. Similar irradiation treatments were performed on fiber samples; in this case, $\mathrm{E}^{\prime}$ centers could be observed only by second harmonic mode, due to their low concentration. Fig. 4(B) shows that $\mathrm{E}^{\prime}$ concentration grows with the UV fluence up to $55 \mathrm{~J} / \mathrm{cm}^{2}$, after that it saturates at a value of $8 \times 10^{15} \mathrm{~cm}^{-3}$.

The absence of NBOHC, ensured by luminescence measurements on preform within $\sim 10^{15} \mathrm{~cm}^{-3}$, indicates that the radiolysis of strained $\mathrm{Si}-\mathrm{O}$ bonds is an unlikely process in our F-doped silica samples. These results point out that the generation of $\mathrm{E}^{\prime}$ centers is due to the conversion of pre-existing precursors, such as oxygen vacancy or extrinsic $\mathrm{Si}-\mathrm{H}$ or $\mathrm{Si}-\mathrm{F}$ bonds, both in preforms and in fibers, but it not involves strained bonds. This is consistent with the growth curve observed under UV irradiation, that 

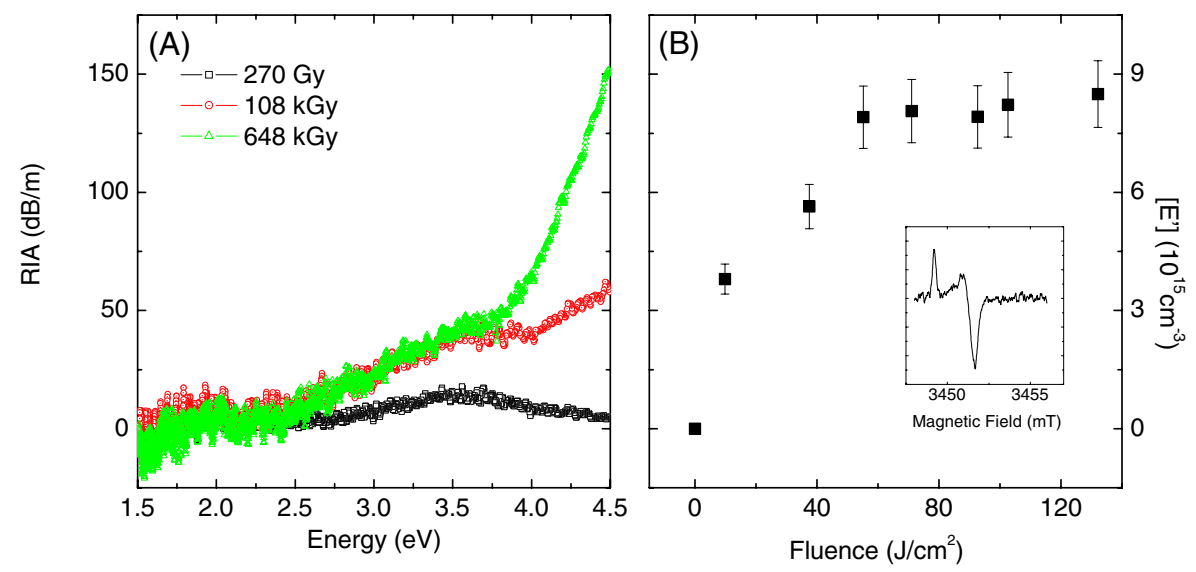

Figure 4. A: spectral radiation-induced attenuation (RIA) as a function of the total $\mathrm{X}-10 \mathrm{keV}$ deposited dose detected in F-doped fiber samples. B: $\mathrm{E}^{\prime}$ concentration as a function of the UV energy fluence on F-doped fibers. The inset shows EPR first harmonic spectrum in UV $\left(8 \times 10^{3} \mathrm{~J} / \mathrm{cm}^{2}\right)$ irradiated F-doped preform with the typical signature of $\mathrm{E}^{\prime}$ centers.

manifests a saturating tendency due to the exhaustion of precursors. These points qualitatively evidence the role of F-doping in governing the response to radiation of preform and fiber: fluorine inhibits the formation of strained bonds and consequently the simultaneous generation of $\mathrm{E}^{\prime}$ and NBOHC.

We are also able to compare the effect of the radiation exposure on fibers and preforms on F-doped samples. Considering the saturation value of $\mathrm{E}^{\prime}$ concentration on UV irradiated fibers, we can evaluate the ratio between this concentration and that found in preforms after an UV fluence of $8 \times 10^{3} \mathrm{~J} / \mathrm{cm}^{2}$ : $\left[\mathrm{E}^{\prime}\right]_{\text {fiber-satur }} /\left[\mathrm{E}^{\prime}\right]_{\text {pref }} \simeq 1.5$ : the same amount of $\mathrm{E}^{\prime}$ centers is generated in fiber and preforms in F-doped samples.

\section{CONCLUSIONS}

We studied the effect of different radiation exposures on F-doped and Ge-doped fibers and preforms.

We have found that, under X-rays, Ge presence causes intense losses in the UV-visible range. The use of complementary spectroscopic techniques allows the identification of the defect species responsible for these losses. Furthermore, the drawing effect has a crucial role in defect formation: at low doses defect generation is 10 times greater in fibers than in preforms.

The introduction of $\mathrm{F}$ also in the fiber core can, on the contrary, ameliorate the fiber resistance: under $\mathrm{X}$ or UV exposure only $\mathrm{E}^{\prime}$ are generated, confirming the role of F-doping in forbidding the generation of strained $\mathrm{Si}-\mathrm{O}$ bonds. For F-doped samples the drawing process does not weaken significantly the radiation toughness: fiber/preforms defect concentration ratio is $\sim 1.5$ at all doses.

Our results allow to conclude that F-doping improves the radiation hardness of fiber samples to respect to Ge-doped ones: fluorine is a promising key material in optical fiber technology directed to applications requiring high and stable transmission in UV and visible spectral range.

\section{References}

[1] H.S. Nalwa, Silicon-Based Materials and Devices (Academic, San Diego, 2001)

[2] G. Pacchioni, L. Skuja, D.L. Griscom, Defects in $\mathrm{SiO}_{2}$ and Related Dielectrics : Science and Technology (Kluwer, Dordrecht, 2000)

[3] G. Meltz, W.W. Morey, W.H. Glenn, Opt. Lett. 14, 823 (1989) 
[4] M. Cannas, G. Origlio, Phys. Rev. B 75, 233201 (2007)

[5] L. Skuja, J. Non-Cryst. Solids 239, 16 (1998)

[6] D.L. Griscom, J. of Non-Cryst. Solids 349, 139 (2004)

[7] S. Girard, J. Keurinck, Y. Ouerdane, J. Meunier, A. Boukenter, J. Lightwave Technol. 22, 1915 (2004)

[8] A.L. Tomashuk, K.M. Golant, E.M. Dianov, O.I. Medvedkov, O.A. Plaksin, V.A. Stepanov, P.A. Stepanov, P.V. Demenkov, V.M. Chernov, S.N. Klyamkin, IEEE Transactions on Nuclear Science 47, 693 (2000)

[9] J. Nishii, N. Fukumi, H. Yamanaka, K. Kawamura, H. Hosono, H. Kawazoe, Phys. Rev. B 52, $1661(1995)$

[10] H. Hosono, Y. Abe, D. Kinser, R. Weeks, K. Kawazoe, Phys. Rev. B 46, 1445 (1992)

[11] S. Agnello, R. Boscaino, M. Cannas, F.M. Gelardi, Phys. Rev. B 64, 174423 (2001)

[12] E. Friebele, D. Griscom, G. Siegel, J. Appl. Phys. 45, 3424 (1974)

[13] J. Nishi, K. Kintaka, H. Hosono, H. Kawazoe, M. Kato, K. Muta, Phys. Rev. B 60, 7166 (1999)

[14] T. Tsai, D. Griscom, E.J.Friebele, J.W.Fleming, J. Appl. Phys. 62, 2264 (1987)

[15] V.B. Neustrev, J. Phys. Condens. Matter 6, 6901 (1994)

[16] M. Fujimaki, T. Watanabe, T. Katoh, T. Kasahara, N. Miyazaki, Y. Ohki, H. Nishikawa, Phys. Rev. B 57, 3920 (1998)

[17] J.W. Fleming, D.L. Wood, Appl. Optics 22, 3102 (1983)

[18] K. Kajihara, Y. Ikuta, M. Oto, M. Hirano, L. Skuja, H. Hosono, Nucl. Instr. and Meth. B 218, 323 (2004)

[19] C.M. Smith, L.A. Moore, J. Fluorine Chem. 122, 81 (2003)

[20] R.E. Youngman, S. Sen, J. Non-Cryst. Solids 337, 182 (2004)

[21] G. Origlio, A. Boukenter, S. Girard, N. Richard, M. Cannas, R. Boscaino, Y. Ouerdane, Nucl. Instrum. Methods B 266, 2918 (2008)

[22] M.O. Zabezhailov, A.L. Tomashuk, I.V. Nikolin, K.M. Golant, IEEE Transactions on Nuclear Science 49, 1410 (2002) 